sexual risk-taking and perceptions of monitoring, communication, and parenting styles", J Adolesc Health. 33(2), tr. 71-8.

4. K. Phongluxa và các cộng sự. (2020), "Factors influencing sexual and reproductive health among adolescents in Lao PDR", Glob Health Action. 13(sup2), tr. 1791426.

5. Ann M. Starrs và các cộng sự. (2018), "Accelerate progress-sexual and reproductive health and rights for all: report of the GuttmacherLancet Commission", The Lancet. 391(10140), tr.
2642-2692.

6. T. A. Yadeta, H. K. Bedane và A. K. Tura (2014), "Factors affecting parent-adolescent discussion on reproductive health issues in Harar, eastern Ethiopia: a cross-sectional study", J Environ Public Health. 2014, tr. 102579.

7. Amsale Cherie Yemane Berhanie (2015), "Assessment of Parenting Practices and Styles and Adolescent Sexual Behavior among High School Adolescents in Addis Ababa, Ethiopia", Journal of AIDS \& Clinical Research. 06(02).

\title{
NGHIÊN CỨU SỰ THAY ĐỔI AFP, AFP-L3, PIVKA-II TRƯớC VÀ SAU ĐIỀU TRI BỆNH NHÂN UNG THƯ BIỂU MÔ TẾ BÀO GAN
}

\section{TÓM TẮT}

Mục tiêu: Mục đích của nghiên cứu đánh giá vai trò của bô ba marker AFP, AFP-L3, PIVKA-II trong việc đánh giá điều trị của bệnh nhân ung thư biểu mô tế bào gan. Đối tượng và phương pháp: Tổng số nghiên cứu trên 29 bệnh nhân ung thư biểu mô tể bào gan tham gia nghiên cứu được đánh giá đặc điểm lâm sàng, cận lâm sàng và sự đáp ứng của AFP, AFP-L3, PIVKA-II sau điều trị 1 tháng và 3 tháng. Kết quả: Trong 29 bệnh nhân, tuổi trung bình của bệnh nhân là $60,5 \pm 10,1$ tuổi. Các yếu tố nguy cơ của ung thư gan là viêm gan virus $B, C$ và rượu. Kết hợp 3 marker AFP AFP-L3 và PIVKA-II giúp làm tăng độ nhạy trong chẩn đoán HCC so với việc sử dụng đơn độc từng marker. Sau điều trị 1 tháng và 3 tháng bằng phương pháp TACE hoăc RFA ở bênh nhân HCC, nồng đồ huyết thanh trung bình của các marker AFP, AFP-L3 và PIVKA-II giảm so với trước điều trị Kết luận: Kết hợp 3 marker AFP, AFP-L3 và PIVKA-II giúp tăng khả năng dư báo đáp ứng về chẩn đoán hình ảnh sau điều trị bệnh nhân ung thư biểu mô tế bào gan so với việc sử dưng đơn đôc từng marker.

Tư khóa: AFP, AFP-L3 và PIVKA-II, ung thư biểu mô tế bào gan.

\section{SUMMARY \\ RESEARCH ON CHANGES OF AFP, AFP-L3, PIVKA-II BEFORE AND AFTER TREATMENT OF HEPATOCELLULAR CARCINOMA}

Objective: The purpose of this study is to evaluate the role of three markers AFP, AFP-L3, PIVKA-II in evaluating the treatment of patients with hepatocellular carcinoma. Subjects and methods: A total 29 patients with hepatocellular carcinoma participating in the study evaluated the clinical,

${ }^{1}$ Trung tâm tiêu hóa gan mật bệnh viện Bạch mai Bệnh viện đa khoa Hà Đông

Chịu trách nhiệm chính: Nguyễn Công Long

Email: nguyenconglongbvbm@gmail.com

Ngày nhận bài: 13.9.2021

Ngày phản biện khoa học: 10.11.2021

Ngày duyệt bài: 17.11.2021

\section{Nguyễn Công Long1, Nguyễn Bá Vượng}

laboratory and response characteristics of AFP, AFPL3, PIVKA-II after 1 month of treatment and 3 months. Results: In 29 patients, the mean age of patients was $60.5 \pm 10.1$ years. The risk factors for liver cancer are hepatitis $B$ and $C$ viruses and alcohol. The combination of three markers AFP, AFP-L3 and PIVKA-II increases the sensitivity in the diagnosis of HCC compared with the use of each marker alone. After 1 month and 3 months of treatment with TACE or RFA in HCC patients, mean serum levels of AFP, AFP-L3 and PIVKA-II markers decreased compared with before treatment. Conclusions: The combination of three markers AFP, AFP-L3 and PIVKAII increases the predictive power of imaging response after treatment of HCC patients compared with the use of each marker alone.

Keywords. AFP, AFP-L3, PIVKA-II and Hepatocellular carcinoma.

\section{I. ĐĂT VẤN ĐỀ}

Ung thư biểu mô tế bào gan là một trong những loại ung thư phổ biến nhất trên thế giới, là loại ung thư có số người mắc đứng thứ 5 ở nam giới và đứng thứ 7 ở nữ giới, nó cũng là một trong ba loại ung thư gây tử vong nhiều nhấttrên toàn thể giới $[1,2]$. Cùng với chẩn đoán hình ảnh, các marker khối u có một vai trò quan trọng trong việc chẩn đoán cũng như theo dõi kết quả điều trị và theo dõi sự tái phát của ung thư biểu mô tế bào gan. Tuy nhiên các nghiên cứu gần đây cho thấy AFP chỉ tăng trong khoảng $60 \%$ các trường hợp HCC và trên thực tế lâm sàngcó nhiều bệnh nhân không đáp ứng với điều trịnhưng nồng độ AFP trong huyết thanhlại giảm một cách rõ rệt sau điều trị. Đó chính là những hạn chế của AFP trong việc chẩn đoán và theo dối sau điều trị HCC.

Trong khi đó AFP-L3 và PIVKA-II là những marker khối u được phát hiện và ứng dụng sau AFP, giúp tăng khả năng chẩn đoán HCC. Trên thế giới đã có nhiều công trình nghiên cứu khẳng 
định vai trò của sự kết hợp AFP-L3 với PIVKA-II và $A F P$ so với $A F P$ đơn thuần trong việc chẩn đoán cũng như đánh giá kết quả điều trị và theo dõi sự tái phát của ung thư biểu mô tế bào gan [3]. Vì vậy chúng tôi tiến hành nghiên cứu về vai trò của bộ 3 marker này trong việc đánh giá kết quả sau điều trị của ung thư biểu mô tế bào gan.

\section{II. ĐỐI TƯợNG VÀ PHƯƠNG PHÁP NGHIÊN CỨU}

Đối tượng: Là các bênh nhân đượcchẩn đoán xác định HCC theo hướng dẫn của bộ Y tễ năm 2012. Trong nghiên cứu này chúng tôi chọn các bệnh nhân HCC chưa từng được áp dụng phương pháp điều trị đặc hiêu nào trước đó, bệnh nhân được làm xét nghiệm định lượng bố ba marker (AFP, AFP-L3, PIVKA-II) và phải có ít nhất 1 trong 3 marker khối u có nồng độ trên ngương bình thường (AFP $>10 \mathrm{ng} / \mathrm{mL}$, AFP-L3 $>10 \%$, PIVKA-II $>40 \mathrm{mAU} / \mathrm{mL}$ ). Tiêu chuẩn loại trừ các bệnh nhân không đồng ý tham gia nghiên cứu.

Phương pháp: nghiên cứu mô tả, tiến cứu, theo dõi dọc.

- Trong nghiên cứu này chúng tôi chọn được 29 bệnh nhân tham gia nghiên cứu để đánh giá đặc điểm lâm sàng, cận lâm sàng và sự đáp ứng của AFP, AFP-L3, PIVKA-II sau điêu trị 1 tháng và 3 tháng.

Các biến số về xét nghiệm

- Nồng độ AFP huyết thanh trước điều trị.

- Nồng độ AFP huyết thanh sau điều trị 1 tháng và 3 tháng.

- Nồng độ AFP-L3 huyết thanh trước điều trị.

- Nồng độ AFP-L3 huyết thanh sau điều trị 1 tháng và 3 tháng.

- Nồng độ PIVKA-II huyết thanh trước điều trị.

- Nồng độ PIVKA-II huyết thanh sau điều trị 1 tháng và 3 tháng.
- Tình trạng đáp ứng của AFP sau điều trị 1 tháng và 3 tháng.

- Tình trạng đáp ứng của AFP-L3 sau điều trị 1 tháng và 3 tháng.

- Tình trạng đáp ứng của PIVKA-II sau điều trị 1 tháng và 3 tháng.

Các biến số về Cắt lớp vi tính hoặc cộng hưởng từ

- Số lượng khối u gan trên CĐHA trước điều trị.

- Kích thước khối u gan trên CĐHA trước điều trị.

-Tình trạng đáp ứng của CĐHA theo mRECIST sau điêu trị 1 tháng.

-Tình trạng đáp ứng của CĐHA theo mRECIST sau điều trị 3 tháng.

Xử lý số liệu: Sau khi thu thâp đầy đủ các số liệu, quá trình xử lý được làm trên máy tính với phần mềm xử lý số liệu SPSS 16.0, tính hệ sô tương quan $r$, giá trị $P<0,05$ được xác định là mức khác biệt có ý nghĩa thống kê.

\section{KẾT QUẢ NGHIÊN CỨU}

Tỷ lệ \%

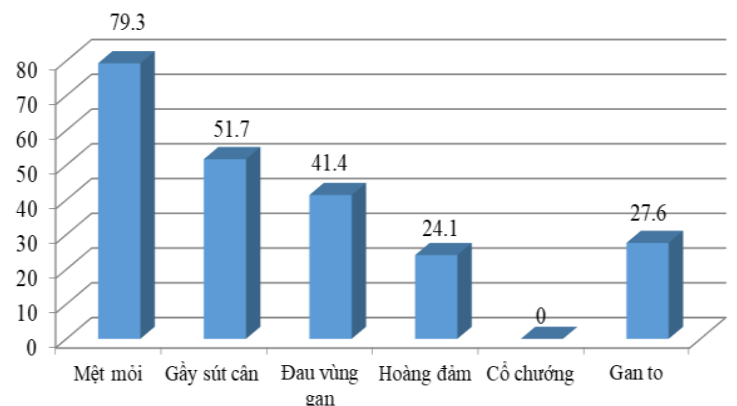

Biểu đồ 1. Đặc điểm lâm sàng nhóm bệnh nhân nghiên cứu

Các triệu chứng lâm sàng hay gặp nhất là mệt mỏi chiếm tỷ lệ $79,3 \%$ và gây sút cân chiếm $51,7 \%$.

Bảng 1. Giai đoạn ung thư biểu mô tế bào gan theo Barcelona (BCLC)

\begin{tabular}{|c|c|c|c|c|c|c|}
\hline BCLC & $\mathbf{0}$ & A & B & C & D & Tống \\
\hline $\mathbf{n}$ & 2 & 11 & 16 & 0 & 0 & 29 \\
\hline$\%$ & 6,9 & 37,9 & 55,2 & 0 & 0 & 100 \\
\hline
\end{tabular}

Bênh nhân ở giai đoạn $\mathrm{BCLC} B$ chiếm tỷ lệ cao nhất $(55,2 \%)$, bệnh nhân ở giai đoạn $\mathrm{BCLC} A$ chiếm $37,9 \%$, ở giai đoạn BCLC 0 chiếm 6,9\%.

Bảng 2. Kích thước khôi u gan trước điều trị

\begin{tabular}{|c|c|c|c|c|c|}
\hline Kích thước khối u (cm) & $\mathbf{5 2}$ & $\mathbf{2 , 1 - 3}$ & $\mathbf{3 , 1 - 5}$ & $\mathbf{7 5}$ & Tống \\
\hline $\mathbf{n}$ & 21 & 9 & 10 & 10 & 50 \\
\hline $\mathbf{\%}$ & 42 & 18 & 20 & 20 & 100 \\
\hline \multicolumn{2}{|r}{ Kích thước trung bình khối u: $3,13 \pm 2,22 \mathrm{~cm}$} \\
\hline
\end{tabular}

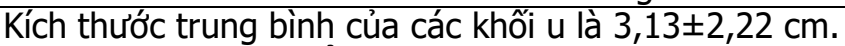

\section{Bảng 3. Giá trị chẩn đoán của các marker khôii u}

\begin{tabular}{|c|c|c|c|c|c|}
\hline \multirow{2}{*}{ Marker (n=29) } & \multicolumn{2}{|c|}{ Caó trị } & \multicolumn{2}{c|}{ Bình thường } & Độ \\
\cline { 2 - 5 } & $\mathbf{n}$ & $\mathbf{\%}$ & $\mathbf{n}$ & $\mathbf{\%}$ & nhạy \\
\hline AFP (Cut off $10 \mathrm{ng} / \mathrm{ml})$ & 22 & 75,9 & 7 & 24,1 & 75,9 \\
\hline
\end{tabular}




\begin{tabular}{|c|c|c|c|c|c|}
\hline AFP-L3 (Cut off 10\%) & 20 & 69,0 & 9 & 31,0 & 69,0 \\
\hline PIVKA-II (Cut off 40 mAU/ml) & 24 & 82,8 & 5 & 17,2 & 82,8 \\
\hline Bộ ba marker & 29 & 100 & 0 & 0 & 100 \\
\hline
\end{tabular}

Số bệnh nhân có AFP cao chiếm75,9\%, AFP-L3 cao chiếm 69,0\%, PIVKA-II cao chiếm 82,8\%.

\begin{tabular}{|c|c|c|c|} 
Bảng 5. Phương pháp điều trị của bệnh nhân \\
\hline Phương pháp & TACE & RFA & Tống \\
\hline $\mathbf{n}$ & 23 & 6 & 29 \\
\hline$\%$ & 79,3 & 20,7 & 100 \\
\hline
\end{tabular}

Số bệnh nhân được điều trị bằng TACE chiếm 79,3\%, điều trị bằng RFA chiếm 20,7\%.

Bảng 6. Sự thay đổi nồng độ trung bình các marker khối u sau 1 tháng

\begin{tabular}{|c|c|c|}
\hline Giá trị & Trước điêu trị & Sau điêu trị $\mathbf{1}$ tháng \\
\hline Marker $(\mathbf{n = 2 9})$ & $173,76 \pm 449,89$ & $82,66 \pm 175,79$ \\
\hline AFP(ng/mL) & $22,94 \pm 23,55$ & $13,40 \pm 18,55$ \\
\hline PIVKA-II $(\mathrm{mAU})$ & $962,48 \pm 2173,42$ & $418,61 \pm 839,45$ \\
\hline
\end{tabular}

Giá trị trung bình của AFP sau điều trị 1 tháng giảm có ý nghĩa so với trước điêu trị $(p=0,010)$.

Bảng 7. Sư thay đổi nồng độ trung bình các marker khôi u sau 3 tháng

\begin{tabular}{|c|c|c|c|}
\hline Marker & áp ứng & $\begin{array}{c}\text { Sau } 1 \\
\text { tháng } \\
(\%)\end{array}$ & $\begin{array}{c}\text { Sau } 3 \\
\text { tháng } \\
(\%)\end{array}$ \\
\hline AFP & $n=22$ & 68,2 & 86,4 \\
\hline AFP-L3 & $n=20$ & 65,0 & 85,0 \\
\hline PIVKA-II & $n=24$ & 79,2 & 87,5 \\
\hline Bô̂ ba marker & $n=29$ & 58,6 & 79,3 \\
\hline
\end{tabular}

Tỷ lệ đáp ứng sau điều trị 1 tháng và 3 tháng của các marker là $58,6 \%$ và $79,3 \%$.

\section{BÀN LUÂNN}

Trong nghiên cứu của chúng tôi, tuổi mắc bênh trung bình của bệnh nhân là $60,45 \pm 10,01$, tuổi mắc bệnh trẻ nhất là 37 , cao nhất là 77 tuổi, nhóm tuổi có tỷ lệ mắc bệnh cao nhất là 51-70 tuổi. Ở Việt nam có tỷ lệ mắc HBV cao, như nghiên cứu này của chúng tôi là $75,9 \%$ số bệnh nhân mắc HBV. Nghiên cứu của chúng tôi, tỷ lệ bệnh nhân ở giai đoạn BCLC $B$ chiếm tỷ lệ cao nhất $(55,2 \%)$, bệnh nhân ở giai đoạn BCLC $A$ chiếm $37,9 \%$, ở giai đoạn BCLC 0 chiếm $6,9 \%$, không có bệnh nhân nào ở giai đoạn $B C L C ~ C$ và BCLC D. Đa số các trường hợp HCC phát triển trên nền gan xơ, xơ gan càng nặng thì khả năng bị HCC càng cao. Kết quả nghiên cứu của chúng tôi cho thây khi kết hợp 3 marker thì độ nhạy trong chẩn đoán HCC tăng lên. Nghiên cứu của Song năm 2013 [4]cũng như nghiên cứu của Gao năm 2017 và nghiên cứu của Lim năm 2016 cho thây độ nhạy và độ đặc hiệu trong chẩn đoán HCC được cải thiện khi sử dụng kết hợp 3 marker khối u AFP, AFP-L3 và PIVKA-II so với khi sử dụng đơn độc từng marker khối u [5]. Nghiên cứu của chúng tôi trên 29 bệnh nhân có tất cả 50 khối u gan, trong đó bệnh nhân có 1 khối u gan chiếm tỷ lệ cao nhất là $44,8 \%$, bệnh nhân có 2 khối u chiếm tỷ lệ 38,0\%, bệnh nhẩn có 3 khối u chiếm tỷ lệ $17,2 \%$. Theo kết quả nghiên cứu của chúng tối 22 bệnh nhân có AFP cao trước điều trị $(75,9 \%), 20$ bệnh nhân có AFP-L3 cao trước điều trị (69,0\%), 24 bệnh nhân có PIVKAII cao trước điều trị $(82,8 \%)$. Vậy nên độ nhạy của các marker AFP (cut off $10 \mathrm{ng} / \mathrm{ml}$ ), AFP-L3 (cut off $10 \%$ ) và PIVKA-II (cut off $40 \mathrm{mAU} / \mathrm{ml}$ ) trong chẩn đoán HCC tương ứng là $75,9 \%$, $69,0 \%$ và $82,8 \%$. Kết quả nghiên cứu cũng cho thấy tình trạng tăng của AFP, AFP-L3 và PIVKA-II trước điêu trị là không có mối liên quan với nhau, nghĩa là 3 marker này có giá trị độc lập trong chẩn đoán HCC. Kết quả này cũng tương tự với kết quả của các nghiên cứu trên thế giới. Nghiên cứu của Bertino năm 2010 kết luận AFP và PIVKA-II có giá trị độc lập trong chẩn đoán HCC[6]. Kết quả nghiên cứu của chúng tôi cho thấy với giá trị cut off là mức giảm $\geq 20 \%$ nồng độ sau điều trị thì tỷ lệ đáp ứng của các marker ung thư như sau: tỳ lệ đáp ứng của AFP là $68,2 \%$ và $86,4 \%$ tương ứng sau điều trị 1 tháng và 3 tháng, tỷ lệ đáp ứng của AFP-L3 là $65,0 \%$ và $85,0 \%$ tương ứng sau điêuu trị 1 tháng và 3 tháng, tỷ lệ đáp ứng của PIVKA-II là $79,2 \%$ và $87,5 \%$ tương ứng sau điều trị 1 tháng và 3 tháng, tỷ lệ đáp ứng của bộ ba marker là $58,6 \%$ và $79,3 \%$ tương ứng sau điều trị 1 tháng và 3 tháng. Tỷ lệ bệnh nhân đáp ứng về AFP và PIVKA-II trong nghiên cứu của chúng tôi thấp hơn trong nghiên cứu của Park và cộng sự năm 2012 trên các bệnh nhân điều trị bằng TACE (91,1\% và $91,4 \%$ tương ứng cho đáp ứng của AFP và PIVKA-II) [7]. Trong nhóm bệnh nhân có AFP bình thường, tỳ lệ đáp ứng của AFP-L3 và của PIVKA-II sau 3 tháng cũng cao hơn sau 1 tháng. 


\section{KẾT LUÂN}

Qua nghiên của chúng tôi cho thấy AFP, AFPL3 và PIVKA-II có giá trị cao trong chẩn đoán ung thư biểu mô tế bào gan và bộ ba marker này sau điều trị 1 tháng và 3 tháng giảm có ý nghĩa so với trước điều trị.

\section{TÀI LIÊU THAM KHẢO}

1. Bertuccio $P$, Turati $F$, Carioli $G$, Rodriguez $T$, La Vecchia C, Malvezzi M, Negri E: Global trends and predictions in hepatocellular carcinoma mortality. Journal of hepatology 2017, 67(2):302-309.

2. Bosetti $C$, Turati F, La Vecchia C: Hepatocellular carcinoma epidemiology. Best practice \& research Clinical gastroenterology 2014, 28(5):753-770

3. Park H, Park JY: Clinical significance of AFP and PIVKA-II responses for monitoring treatment outcomes and predicting prognosis in patients with hepatocellular carcinoma. BioMed research international 2013, 2013:310427.
4. Song $\mathbf{P}$, Gao J, Inagaki $\mathbf{Y}$, Kokudo $\mathbf{N}$, Hasegawa $K$, Sugawara $\mathbf{Y}$, Tang $\mathbf{W}$ : Biomarkers: evaluation of screening for and early diagnosis of hepatocellular carcinoma in Japan and china. Liver cancer 2013, 2(1):31-39.

5. Lim TS, Kim DY, Han KH, Kim HS, Shin SH, Jung KS, Kim BK, Kim SU, Park JY, Ahn SH: Combined use of AFP, PIVKA-II, and AFP-L3 as tumor markers enhances diagnostic accuracy for hepatocellular carcinoma in cirrhotic patients. Scandinavian journal of gastroenterology 2016, 51(3):344-353.

6. Bertino G, Ardiri AM, Calvagno GS, Bertino N, Boemi PM: Prognostic and diagnostic value of des-y-carboxy prothrombin in liver cancer. Drug news \& perspectives 2010, 23(8):498-508.

7. Park WH, Shim JH, Han SB, Won HJ, Shin YM, Kim KM, Lim YS, Lee HC: Clinical utility of des- $\gamma$-carboxyprothrombin kinetics as a complement to radiologic response in patients with hepatocellular carcinoma undergoing transarterial chemoembolization. Journal of vascular and interventional radiology: JVIR 2012, 23(7):927-936.

\title{
THỰC TRANG TỔNG DUNG TÍCH PHỔI (TLC) Ở NGƯờI TIẾP XÚC TRỰC TIẾP BỤI SILIC TRONG MÔI TRƯỜNG LÀM VIỆC VÀ YẾU TỐ LIÊN QUAN
}

\author{
Nguyễn Ngọc Anh, Lê Thị Thanh Xuân, Nguyễn Thanh Thảo, \\ Lê Thị Hương, Phạm Thị Quân, Nguyễn Thị Quỳnh(*)
}

\section{TÓM TẮT}

Một nghiên cứu mô tả được thực hiện với mục tiêu đánh giá sự thay đổi tổng dung tích phổi (TLC) ở 869 đối tượng nghiên cứu là những người tiếp xúc trực tiếp bụi silic trong quá trình làm việc, đã được chụp phim xquang phối theo tiêu chuẩn ILO để chẩn đoán bụi phổi silic. Sau đó các đối tượng được đo chức năng hô hấp và đo tổng dung tích phổi (TLC). Kết quả cho thây: Tỷ lệ người lao động có giảm TLC là 10,5\% (91/869); có mối liên quan chặt chẽ giữa mắc bụi phổi silic đám mờ lớn với suy giảm TLC $(p<0,001)$; chưa thấy có mối liên quan giữa mắc bụi phổi silic nốt mờ nhỏ với sự suy giảm TLC ( $p>0,05)$; Có mối liên quan chặt chẽ giữa các mức độ giảm chỉ số FVC với giảm TLC trong phân tích đớn biến và đa biến $(p<0,001)$. Nên tiếp tục sử dụng các kỹ thuâat, chỉ số đo chức năng hô hấp thông thường như FVC để đánh giá giảm chức năng hô hấp hạn chế, trong trường hợp cần sự chính xác cao thì dùng chỉ số kỹ thuật cao TLC.

Tử khóa: Tổng dung tích phổi, chức năng hô hấp

\section{SUMMARY}

THE TOTAL LUNG CAPACITY AMONG

(*)Viên ĐT YHDP \& YTCC, Đai hoc Y Hà Nọi

Chịu trách nhiệm chính: Nguyễn Ngọc Anh

Email: anhnn@hmu.edu.vn

Ngày nhận bài: 14.9.2021

Ngày phản biên khoa hoc: 12.11.2021

Ngày duyệt bài: 19.11.2021

\section{WORKERS EXPOSED TO SILICA DUST IN} THE WORKPLACE AND RELATED FACTORS

This descriptive study aims to examine the changes in total lung capacity of workers who are directly exposed to silica in the workplace and related factors. Before measuring the respiratory function and total lung capacity (TLC), 869 workers in the environment exposed to silica dust had taken chest $\mathrm{x}$ rays to diagnose silicosis. The results show that: TLC reduction rate is $10.5 \%(91 / 869)$; there is a close relationship between having large cloud silicosis with TLC decline $(p<0.001)$; no association between small nodular silicosis and TLC decline $(p>0.05)$; There is a close relationship between the FVC reduction and TLC reduction $(p<0.001)$. It is recommended to continue to use common techniques and indicators of respiratory function such as FVC to assess limited respiratory function decline, in case high accuracy is required, the high technical index TLC should be used. function

Keywords; Total lung capacity, respiratory

\section{I. ĐẠT VẤN ĐỀ}

Tổng dung tích phổi (TLC) là lượng khí chứa trong phổi sau khi hít vào tối đa. Trung bình thể tích này ở người trưởng thành là khoảng 6 lít, tuy nhiên thể tích này còn phụ thuộc vào tuổi, giới, tình trạng cơ thể. TLC ở nam giới có xu hướng lớn hơn nữ, người có vóc dáng cao lớn hơn người thấp bé. Ngoài ra, TLC khác nhau ở 